\begin{tabular}{|c|c|c|}
\hline $\begin{array}{l}\text { PUCRS } \\
\text { PUCR }\end{array}$ & $\begin{array}{l}\text { ESCOLA DE } \\
\text { HUMANIDADES }\end{array}$ & $\begin{array}{l}\text { Revista Digital do Programa de Pós-Graduação em Letras da PUCRS } \\
\text { Letrônica, Porto Alegre, v. 13, n. 4, p. 1-16, out.-dez. } 2020 \\
\text { e-ISSN: } 1984-4301\end{array}$ \\
\hline ditp: $/ / \mathrm{dx}$ & $\mathrm{rg} / 10.15448 / 1984-4301.2020 .4 .37314$ & \\
\hline
\end{tabular}

SEÇÃO: ARTIGOS

\title{
Avaliação em larga escala na educação superior e a proficiência em leitura no contexto acadêmico
}

\author{
Large-scale assessment in higher education and reading proficiency \\ in the academic context
}

\author{
Sammela Rejane de \\ Jesus Andrade ${ }^{1}$ \\ orcid.org/0000-0002-9845-4101 \\ sammela88@yahoo.com.br
}

Recebido em 9/3/2020. Aprovado em 8/6/2020. Publicado em: 21/12/2020.
Resumo: A concepção de proficiência em leitura preconiza que os indivíduos sejam ativos no meio social, de modo que consigam compreender e interagir com as informações que os cercam. Espera-se que essa mesma concepção esteja prevista em todo processo educacional, com vistas que os estudantes sejam formados enquanto leitores proficientes, e, em composição desse processo, também esteja prevista nas avaliações em larga escala, haja vista que entre as suas funções está a de avaliar as mais diferentes etapas de ensino e orientar o planejamento de políticas públicas. Todavia, o que se tem visto, com frequência, são muitas queixas dos agentes diretamente envolvidos, professores e alunos, e dados alarmantes a cada relatório divulgado pelos órgãos competentes. Tratando-se mais especificamente do desempenho em leitura no contexto acadêmico, avaliações como o Exame Nacional do Ensino Médio (Enem) e o Exame Nacional de Desempenho dos Estudantes (Enade) demonstram uma quebra de expectativa, pois, mesmo após cursar anos da educação básica, alunos têm adentrado a universidade com deficiência em leitura, e mais preocupante ainda é o fato de estarem matriculados ou terem concluindo o curso de nivel superior e as dificuldades ainda persistirem. Diante disso, o presente estudo tem como proposta abordar a trajetória de progressão de desempenho dos estudantes universitários por meio das duas principais avaliações em larga escala das quais os mesmos participam, o Enem, por ser o mais importante exame de seleção de vagas; e o Enade, por ser avaliação obrigatória a todos os matriculados em cursos de graduação. Para isso, traremos as concepções de competência leitora nos dois exames, além de alguns estudos já realizados sobre leitura e escrita acadêmica. Palavras-chave: Proficiência. Leitura. Enem. Enade.

\begin{abstract}
The concept of reading proficiency recommends that individuals be active in the social environment, so that they can understand and interact with the information that surrounds them. It is expected that this same conception is foreseen in every educational process, with a view to the students being trained as proficient readers, and, in composition of this process, it is also foreseen in the evaluations in large scale, considering that among its functions is the to evaluate the most different teaching stages and guide the planning of public policies. However, what has often been seen are many complaints from the agents directly involved, teachers and students, and alarming data for each report released by the competent bodies. More specifically, in terms of reading performance in the academic context, evaluations such as Enem and Enade demonstrate a broken expectation, because, even after attending years of basic education, students have entered the university with reading disabilities, and even more worrying. The fact that they are enrolled or have completed the higher education course and the difficulties still persist. In light of this, the present study aims to address the trajectory of progression of performance of university students through the two main large-scale assessments in which they participate. Enem, for being the most important exam for the selection of vacancies; and Enade, as it is a mandatory assessment for all those enrolled in undergraduate courses. For this, we will bring the concepts of reading competence in the two exams, in addition to some studies already carried out on academic reading and writing.
\end{abstract}

Keywords: Proficiency. Reading. Enem. Enade. 


\section{Introdução}

O fato de vivermos em uma sociedade letrada, onde as atividades envolvem a leitura vão desde as atividades escolares e de trabalho, até as mais corriqueiras, como usar o transporte público, preconiza que os individuos sejam ativos no meio social, ou seja, proficientes, de modo que consigam compreender e interagir com as informações que os cerca, sendo capaz de ir além da leitura mecânica, pautada apenas na decodificação, que é um passo importante para a realização da leitura, mas não o único necessário para compreender proficientemente o que é lido.

A leitura é o processo no qual o leitor realiza um trabalho ativo de compreensão e interpretação do texto, a partir de seus objetivos, de seu conhecimento sobre o assunto, sobre o autor, de tudo o que sabe sobre a linguagem etc. Não se trata de extrair informação, decodificando letra por letra, palavra por palavra. Trata-se de uma atividade que implica estratégias de seleção, antecipação, inferência e verificação, sem as quais não é possivel proficiência. É o uso desses procedimentos que possibilita controlar o que vai ser lido, permitindo tomar decisões diante de dificuldades de compreensão, avançar na busca de esclarecimentos, validar no texto suposições feitas (BRASIL, 1998, p. 69-70).

Essa concepção de leitura permeia os ideais de formação dos individuos atualmente, inclusive nas avaliações em larga escala, a exemplo do Programa Internacional de Avaliação de Estudantes (Pisa), que indica a proficiência como "uso e compreensão de textos escritos e como reflexão sobre os mesmos, com vistas a alcançar objetivos pessoais, desenvolver o conhecimento e potencial individuais, visando à participação plena na vida em sociedade" (BRASIL, 2011, p. 29). Desse modo, a concepção de proficiência em leitura reside na capacidade do sujeito compreender textos dos mais variados gêneros, a fim de corresponder às expectativas individuais e a do processo cognitivo no qual o texto está inserido.

A mesma prerrogativa está presente no Enem, mais especificamente no primeiro objeto do conhecimento da Matriz de Referência da prova de Linguagens, códigos e suas tecnologias, ao apresentar o estudo do texto, as sequências discursivas (responsáveis pela organização interna do texto) e os gêneros textuais (textos que circulam socialmente e são classificados em gêneros de acordo com as características que apresentam: formato, assunto, destinatário, função, intencionalidade) constituintes do sistema de comunicação e informação, a partir dos quais os alunos devem ser capazes de estabelecer "modos de organização da composição textual; atividades de produção escrita e de leitura de textos gerados nas diferentes esferas sociais" (BRASIL, 2012, p. 4). Além disso, avaliações que compõem o Sistema de Avaliação da Educação Básica (Saeb), a exemplo da Prova Brasil, também avaliam a proficiência do aluno-leitor por meio de questões voltadas para a capacidade de dialogar com variados suportes textuais.

O individuo capaz de interagir com o texto é denominado por Solé (1998, p. 72) como "leitor autônomo", alguém capaz de "[...] estabelecer relações entre o que lê e o que faz parte do seu acervo pessoal, questionar seu conhecimento e modificá-lo, estabelecer generalizações que permitam transferir o que foi aprendido para outros contextos diferentes". Desse modo, a leitura se estabelece como uma atividade critica e proficiente.

Não diferente da educação básica, as atividades que envolvem a prática da leitura na educação superior têm sido alvo de muitas discussões e tema de pesquisas, principalmente na perspectiva de que os alunos apresentam muitas dificuldades, sem a desenvoltura desejada quando são requeridos a desenvolverem atividades que exijam gêneros acadêmicos, tais como, por exemplo, tese, dissertação de mestrado, artigo acadêmico-científico, editorial de jornal, monografia, conferência, artigo de divulgação científica, entre outros, ou seja, gêneros de grande circulação no meio acadêmico. Em

\footnotetext{
Este artigo parte da tese em desenvolvimento Proficiência em leitura: correlações com acesso, permanência e sucesso na educação superior (ANDRADE, 2020) e está vinculado ao projeto Como fala, lê e escreve o universitário (FREITAG, 2019), uma ação de documentação, descrição e formação linguística, a partir de uma pedagogia culturalmente sensivel, com a documentação linguistica para a descrição linguística da fala, da leitura e da escrita de universitários, para subsidiar a elaboração de material didático para cursos de letramento acadêmico. As diferenças linguísticas entre a norma linguística do universitário e a norma padrão (SOUZA; SILVA; MONTEIRO JUNIOR, 2020) são responsáveis pela assimetria no desempenho em leitura (FREITAG, 2020a,2020b), tanto na educação básica como na educação superior.
} 
consequência disso, boa parte das discussões sobre o assunto volta-se para onde se encontra o "calcanhar de Aquiles" da vulnerabilidade de desempenho desses alunos.

Sistematicamente, as fragilidades no processo de transição entre a educação básica e a educação superior emergem - como apontam Silva e Santos (2004), Pietre (2007), Marinho (2010), Fiad (2011), Tourinho (2011), entre outros - sob a ótica de que as instituições de ensino superior recebem os alunos já com domínio dos gêneros acadêmicos, recaindo assim sobre a educação básica a responsabilidade de contemplar, nas aulas língua portuguesa - recepção e produção de texto, tais gêneros.

Todavia, o que temos de realidade é que, na educação básica, os gêneros acadêmicos não são abordados em sua plenitude, quando o assunto é o gênero argumentativo, o mais utilizado no meio acadêmico, as aulas voltam-se para a produção da redação dissertativo-argumentativa, tendo em vista a sua importância nos exames de seleção de vagas para ingresso nas universidades, a exemplo do Enem.

Sabemos, no entanto, que os gêneros acadêmicos não constituem conteúdo e nem práticas preferenciais nas escolas de ensino fundamental médio. A leitura e a escrita de gêneros de referência na academia - artigos, teses, monografias, dissertações, resenhas acadêmicas, entre outros - são realizadas, de preferência, na universidade, porque é nessa instituição que são produzidos, por necessidades próprias, esses gêneros (MARINHO, 2010, p. 366).

Esse cenário é apontado em Andrade (2016), que, por meio de pesquisa realizada com alunos de graduação em Letras da Universidade Federal de Sergipe, constata que as práticas de escrita acadêmica, através da apropriação dos gêneros e da correlação com a redação do Enem, indicam que a prova escrita do exame, por ser de mesmo tipo textual, o dissertativo-argumentativo, tem sido de importante suporte para o desenvolvimento das atividades escritas iniciais da graduação, principalmente quando ainda não se teve contato com disciplinas específicas para a metodologia de produção textual acadêmica.

Além disso, estudos como os de Silva e Santos (2004), Cabral e Tavares (2005), Marinho (2010) Tourinho (2011), Fiad (2011) e Medeiros e Silva
(2012) evidenciam a dificuldade dos alunos universitários em atender a demanda de produção de textos acadêmicos durante seus cursos, perpassando pelas queixas dos professores quanto à baixa qualidade dos textos produzidos e a falta de atividades de extensão ou disciplinas na grade curricular, voltados para o tema.

\begin{abstract}
[...] a crença (subjacente aos discursos de senso comum e aos currículos) no princípio de que se aprende a ler e a escrever (não importa qual seja o gênero) no ensino fundamental $e$ médio. Aos professores universitários, costuma causar estranhamento o fato de encontrar alunos pouco familiarizados com a leitura e a produção de gêneros que sustentam as suas aulas e outros eventos próprios à vida acadêmica (MARINHO, 2010, p. 366).
\end{abstract}

Quanto ao desempenho acadêmico, os alunos que passam pela educação básica e pelos cursos de graduação apresentam muitas dificuldades em produzir textos que correspondam às expectativas. De um lado estão alunos que reconhecem suas dificuldades e professores que se queixam do baixo desempenho desses; do outro, temos um jogo de responsabilidades, no qual as instituições de ensino superior atribuem às escolas a abordagem dos gêneros acadêmicos e a sociedade atribui às universidades o preparo insatisfatório dos professores que fazem parte da educação básica.

É importante também retomar a maior possibilidade de acesso às vagas que se efetivou a partir de políticas públicas voltadas para a democratização do ingresso no ensino superior, porém o mesmo ainda não aconteceu com o número de egressos. O percentual de brasileiros com nivel acadêmico, cerca de 21\% do total da população, ainda é muito pequeno se comparado ao de outros países do mundo, a exemplo da Rússia e Canadá, com mais de $50 \%$ de cidadãos com pelo menos um diploma universitário, respectivamente 53\% e 51\% da população, segundo dados levantados pela Organização para a Cooperação e Desenvolvimento Econômico (OCDE) em 2018, que aponta uma média entre os países participantes de $44 \%$ da população com nível superior. Outro dado apresentado no relatório foi que somente 33\% consegue terminar o curso no tempo esperado.

Existem muitos fatores que podem desenca- 
dear a falta de sucesso na conclusão de cursos de graduação, optamos por nos ater a um deles, o desempenho acadêmico dos alunos, principalmente no que concerne à leitura. Sendo assim, nos propomos a observar como acontece a percepção desse ciclo progressivo de perpetuação de dificuldade dos alunos no desenvolvimento de tarefas acadêmicas, principalmente por vivenciarmos a ampliação das vagas ofertadas nos cursos de graduação e o número de estudantes nos bancos das universidades também ter crescido, uma vez que se parte do princípio de que, com mais estudantes, o problema toma proporções maiores.

A fim de contribuir com a discussão, e em alinhamento ao projeto Como Fala, Lê e Escreve o Universitário? (FREITAG, 2019), observamos o que os documentos balizadores de duas avaliações em larga escala, o Enem e o Enade, discorrem sobre competências e habilidades em leitura, considerando o que preconizam os documentos norteadores: Matriz de Referência do Enem e portarias normativas do Enade, além dos documentos gerais, Parâmetros Curriculares Nacionais (PCN) e Lei de Diretrizes e Bases (LDB), e alguns estudos que também se debruçam sobre a temática aqui proposta.

\section{Avaliações em larga escala: da seleção de vagas à aferição de desempenho}

Nas últimas décadas, as avaliações oficiais têm ganhado destaque no quadro educacional do Brasil, seja como instrumento que mede o desempenho dos alunos na atribuição de notas, seja como método de ingresso em universidades, ou ainda, para acompanhar o sistema educacional do país.

Apesar da visibilidade atual, o Enem não é a única avaliação oficial na educação brasileira: Prova Brasil ${ }^{3}$, Provinha Brasil,, ${ }^{4}$ Enade, entre outras avaliações, fazem parte do cotidiano educacional do país, em meio a um processo de transição acerca da perspectiva do que se considera como "avaliação". Essa deixa de ser apenas um meio de aferição do conhecimento para atribuição de notas e passa a ter proporções maiores, sendo utilizada inclusive como instrumento politico de governo. Segundo Gadotti (1991, p. 16), "a avaliação é essencial à educação, inerente e indissociável enquanto concebida como problematização, questionamento e reflexão sobre a ação."

O fenômeno desse tipo de avaliação que acontece no Brasil é também frequente em muitos outros países, tendo, inclusive, início nos Estados Unidos, já na década de 1930, quando o termo "avaliação educacional" foi primeiramente proposto por Rolfh Tyler, juntamente com a ideia de educação por objetivos, com vistas a auxiliar na aferição do conhecimento (no caso, se os objetivos propostos pelo governo e pelas escolas tinham sido alcançados).

No Brasil, as avaliações deixam de ser apenas práticas escolares na década de 1960, quando surge uma perspectiva mais tecnicista, resultante de exames vestibulares, influenciada pela metodologia americana, que, também nessa década, propôs a aplicação de avaliações como método de acompanhamento de desempenho escolar de alunos com baixo rendimento.

Em 1990, a avaliação rompe de vez os muros da escola, deixando de se restringir ao método de atribuição de notas e passando a ganhar força como um mecanismo do governo para formular e implementar politicas educacionais desde o ensino básico, com a Provinha Brasil, Prova Brasil, Enem, até o superior, com o Enade.

Como instrumento do governo, as avaliações são coordenadas pelo Instituto Nacional de Estudos e Pesquisas Educacionais Anísio Teixeira (Inep), uma autarquia do Ministério da Educação (MEC), e os resultados são utilizados, entre outros, para medir a qualidade do ensino, subsidiar a implementação de políticas públicas, aperfeiçoar o curriculo, desenvolver estudos e indicadores sobre

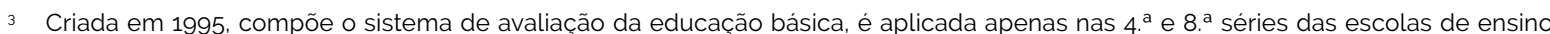
fundamental público da zona urbana, a partir das habilidades envolvidas nas áreas de conhecimento de português e matemática (cf. MACHADO; MATOS, 2019)

4 Avaliação, aplicada desde 2007, que tem por objetivo identificar possiveis problemas no processo de alfabetização das crianças matriculadas no segundo ano do ensino fundamental das escolas públicas brasileiras, através da aplicação semestral de avaliações que investigam as habilidades de leitura e matemática (cf. ALMEIDA; FREITAG, 2012; FREITAG; ALMEIDA; ROSÁRIO, 2013). Foi substituída pela Avaliação Nacional de Alfabetização (ANA) (cf. FREITAG; SÁ, 2019). 
a educação brasileira, por isso é preciso ver até que ponto essas avaliações estão refletindo realmente essa realidade, e, principalmente, dos estudantes que saem da educação básica com vistas a pleitear uma vaga na educação superior, além daqueles que já se encontram nas universidades.

\subsection{Enem enquanto avaliação em larga escala e concepções de leitura subjacentes}

Seguindo a mesma premissa das demais avaliações em larga escala, a de avaliar a educação do país, em 1998, foi criado o Enem, por intermédio da Portaria Ministerial n. ${ }^{\circ} 438$ de 28 de maio de 1998, para avaliar os alunos concluintes ou que já concluíram o ensino médio. Foi elaborado a partir de documentos norteadores como LDB e PCN pelo Inep, e desde então com a proposta de definir políticas públicas voltadas para o ensino médio, a exemplo da disseminação da interdisciplinaridade através das habilidades e competências, como já vinha sendo proposto pela LDB (1996) e o PCNEM (1997).

A fundamentação do exame se dá através de uma matriz que indica a associação de conteúdos, competências e habilidades, que devem ser de domínio dos jovens concluintes dessa etapa de ensino.

Para estruturar o exame, concebeu-se uma matriz com a indicação de competências e habilidades associadas aos conteúdos do ensino fundamental e médio que são próprias ao sujeito na fase de desenvolvimento cognitivo, correspondente ao término da escolaridade básica. Tem como referência a LDB, os Parâmetros Curriculares Nacionais (PCN), a Reforma do Ensino Médio, bem como os textos que sustentam sua organização curricular em Áreas de Conhecimento, e, ainda, as Matrizes Curriculares de Referência para o SAEB (BRASIL, 2000, p. 2).

O exame tem a proposta de avaliar as estruturas mentais que são desenvolvidas ao longo da vida, por intermédio das competências e habilidades compativeis a um aluno que esteja concluindo o ensino médio. Enquanto as avaliações de vestibulares cobram conhecimentos especificos de cada disciplina, o Enem se propõe a avaliar o conjunto de competências, sendo as disciplinas apenas um meio para esse fim (ver Quadro 1).

Quadro 1 - Matriz de Competências do Enem

\begin{tabular}{|l|l|}
\hline I & Dominar a norma culta da Língua Portuguesa e fazer uso das linguagens matemática, artística e científica. \\
\hline II & $\begin{array}{l}\text { Construir e aplicar conceitos das várias áreas do conhecimento para a compreensão de fenômenos } \\
\text { naturais, de processos histórico-geográficos, da produção tecnológica e das manifestações artísticas. }\end{array}$ \\
\hline III & $\begin{array}{l}\text { Selecionar, organizar, relacionar, interpretar dados e informações, representados de diferentes formas, } \\
\text { para tomar decisões e enfrentar situações-problema. }\end{array}$ \\
\hline IV & $\begin{array}{l}\text { Relacionar informações, representadas em diferentes formas, e conhecimentos disponiveis em situa- } \\
\text { ções concretas, para construir argumentação consistente. }\end{array}$ \\
\hline V & $\begin{array}{l}\text { Recorrer aos conhecimentos desenvolvidos na escola para elaboração de propostas de intervenção } \\
\text { solidária na realidade, respeitando os valores humanos e considerando a diversidade sociocultural. }\end{array}$ \\
\hline
\end{tabular}

Fonte: BRASIL, 2000, p. 6.

No que corresponde à prova objetiva, com vistas ao atendimento das habilidades e competências propostas, o guia do participante instituiu o seguinte barema:

A parte objetiva da prova será constituída de 63 (sessenta e três) questões de múltipla escolha de igual valor, avaliada numa escala de zero a 100 (cem) pontos, e gera uma nota global que corresponde à soma dos pontos atribuidos às questões acertadas.
As cinco competências que são avaliadas no Enem na parte objetiva da prova expressam-se por meio de 21 habilidades. Cada uma das 21 habilidades será medida três vezes (três questões para cada habilidade).

A interpretação dessa nota global será estruturada a partir de cada uma das cinco competências, pelas relações estabelecidas com as respectivas habilidades e as questões a elas relacionadas, gerando também para cada competência, uma nota de 0 a 100 (BRASIL, 2000, p. 8). 
Em se tratando das noções de competência e habilidades a serem atingidas pelos candidatos ao realizarem o exame, o documento Base do Enem (2000, p. 5) define esses termos do seguinte modo: "competências" são modalidades estruturais da inteligência, ou seja, ações e operações que utilizamos para estabelecer relações com e entre objetos, situações, fenômenos e pessoas que desejamos conhecer; e as "habilidades" são decorrentes das competências adquiridas e se referem ao plano imediato do "saber fazer". É através das ações e operações que as habilidades se aperfeiçoam e se articulam, possibilitando nova reorganização das competências.

A despeito da aquisição das competências e habilidades, Bloom et al. (1956) apresentam um instrumento, a Taxonomia de Bloom, que tem por finalidade ajudar no planejamento, na organização e no controle dos objetivos de aprendizagem. A partir desse, é possivel que os professores auxiliem seus alunos a adquirirem competências especificas de modo a dominarem habilidades mais simples para, posteriormente, dominar as mais complexas, isso através dominios especificos e com niveis de gradação. Nessa perspectiva, a taxonomia é uma estratégia escolar possivel para preparar os estudantes que farão o Enem.

Decorrente de um processo de mudanças estruturais, em 2009 surge o Novo Enem, promovendo mais mudanças, na medida em que o exame deixa de avaliar apenas o desempenho dos alunos.

Art. $2^{\circ}$ Constituem objetivos do Enem:

I - oferecer uma referência para que cada cidadão possa proceder à sua autoavaliação com vistas às suas escolhas futuras, tanto em relação ao mercado de trabalho quanto em relação à continuidade de estudos;

II - estruturar uma avaliação ao final da educação básica que sirva como modalidade alternativa ou complementar aos processos de seleção nos diferentes setores do mercado de trabalho;

III - estruturar uma avaliação ao final da educação básica que sirva como modalidade alternativa ou complementar aos exames de acesso aos cursos profissionalizantes pós-médios e à Educação Superior;

IV - possibilitar a participação e criar condições de acesso a programas governamentais.

$\checkmark$ - promover a certificação dos jovens e adultos no nivel de conclusão do ensino mé- dio nos termos do artigo $38, \S \S 1^{\circ}$ e $2^{\circ}$ da Lei n 9.394/96 - Lei de Diretrizes e Bases da Educação Nacional (LDB);

VI - promover a avaliação do desempenho acadêmico das escolas de ensino médio, de forma que cada unidade escolar receba o resultado global;

VII - promover a avaliação de desempenho acadêmico de ingressantes nas Instituições de Educação Superior (BRASIL, 2009, p. 56).

Com o Novo Enem, o exame torna-se método de acesso às vagas federais do ensino superior, porém, o processo de adesão das universidades federais ao novo método de seleção de candidatos não se deu de forma imediata e tranquila. Como estratégia para tal fim, o governo federal já havia instituído o Programa de Apoio a Planos e Expansão das Universidades Federais (Reuni), através do Decreto n. ${ }^{\circ}$ 6.096, de 24 de abril de 2007, com o objetivo de criar condições para a ampliação de acesso e permanência na educação superior, sendo o Novo Enem um dos meios para isso.

Enquanto política pública, passou por mudanças ao longo do seu ciclo, principalmente pelo fato de ter acumulado funções, haja vista que seu problema inicial era apenas se configurar enquanto política de avaliação para avaliar o desempenho dos alunos concluintes da educação básica, anos depois sendo necessária a sua reformulação, em 2009, para atender à nova demanda de selecionar os candidatos que pleiteavam uma vaga na educação superior.

Ao acumular funções, já que é uma avaliação de seleção e desempenho, a prova, além de avaliar a educação básica, também é um instrumento de avaliação dos alunos ingressos na educação superior, conforme previsto no artigo $2^{\circ}$ do documento referente ao Novo Enem (BRASIL, 2009, p. 56) "promover a avaliação de desempenho acadêmico de ingressantes nas Instituições de Educação Superior", objetivo também previsto na legislação do Enade.

Por ser um dos mecanismos de avaliação utilizado pelos órgãos governamentais para, entre outras finalidades, subsidiar as políticas educacionais, compõe os índices que medem a qualidade do ensino oferecido ao longo do ensino fundamental e do médio. Zirondi e Nascimento (2006) 
também evidenciam que esse teste serve como "termômetro" para o aluno analisar os próprios conhecimentos e habilidades (em leitura, por exemplo) adquiridos ao longo de sua vida escolar.

As competências e habilidades em leitura e escrita são cobradas de duas formas na avaliação, através da prova objetiva das quatro grandes áreas do conhecimento - Linguagens, códigos e suas tecnologias; ciências humanas e suas tecnologias; matemática e suas tecnologias; e ciências da natureza e suas tecnologias - e da prova dissertativa; sendo exigido do candidato estratégias que otimizem a leitura dos enunciados e alternativas de respostas das 180 questões de múltipla escolha do Novo Enem, além dos textos motivadores da prova de redação.

O exame deve ser analisado como prática de leitura e escrita, as duas grandes tarefas da avaliação. Na primeira parte, o participante deve dissertar sobre um tema proposto, e, na segunda, ler os enunciados das questões e escolher uma, dentre cinco alternativas de respostas. Partindo desse pressuposto pode-se afirmar que o enfoque central do exame é a leitura (CAVALCANTE; BENITES, 2013, p. 6).

Ao analisar a prova de Linguagens, códigos e suas tecnologias - LCTs, de 2011, as autoras identificaram que 70\% das questões eram respondiveis a partir dos procedimentos de leitura e apenas os 30\% restantes dependiam de conhecimentos específicos. E concluem o estudo afirmando que o Enem é uma avaliação de leitura que espera um leitor competente, que, segundo os Parâmetros Curriculares Nacionais (Brasil, 1998b, p. 15), "é alguém que, por iniciativa própria, é capaz de selecionar, dentre os trechos que circulam socialmente, aqueles que podem atender a uma necessidade sua. Que consegue utilizar estratégias de leitura adequada para abordá-los de formas a atender a essa necessidade".

Ainda sobre a existência de dois modelos de avaliação no exame, Zirondi e Nascimento (2006) defendem que a compreensão e produção de textos são aspectos convergentes no que tange ao uso da linguagem. Assim, a avaliação assegura um tratamento interdisciplinar tanto para a produção como para a resolução de situação-pro- blema das questões objetivas. No que tange às situações-problema, as autoras apontam:

\begin{abstract}
A competência em relação à situação-problema se configura como a realização de uma tarefa em que o individuo deve mobilizar recursos, ativar esquemas e tomar decisões. Com essas ações preserva informações do passado para organizar o presente e está capacitado a desafiar o desconhecido, diferenciar e integrar as partes e o todo que estruturam e organizam suas interações com o mundo e consigo mesmo (ZIRONDI; NASCIMENTO, 2006, p. 301).
\end{abstract}

Desse modo, ao oferecer um comando ao candidato, por intermédio do enunciado das questões, espera-se que este construa estratégias de leitura que os leve ao reconhecimento da resposta correta, através da interpretação textual.

Sendo o texto de apoio presença recorrente no comando das questões, é possivel inferir que uma das principais estratégias para conseguir responder a prova objetiva, principalmente de LCTs, é dominar os gêneros textuais; haja vista que o primeiro objeto de conhecimento associado à Matrizes de Referência da Linguagem, Códigos e suas Tecnologias (BRASIL, 2012) é o estudo do texto a partir das sequências discursivas e os gêneros textuais no sistema de comunicação e informação, sendo essa habilidade atingida pelo aluno quando o mesmo apresenta domínio dos modos de organização da composição textual e das atividades de produção escrita e de leitura de textos gerados nas diferentes esferas sociais.

Como gênero textual, adotamos a definição de Marcuschi (2005, p. 30): "os gêneros não são entidades naturais como as borboletas, as pedras, os rios e as estrelas, mas são artefatos culturais construidos historicamente pelo ser humano". Nessa perspectiva, o gênero textual se caracteriza pela materialização dos textos em situações comunicativas, variando de acordo com a sua funcionalidade.

É importante observar que a abordagem voltada para o domínio dos gêneros textuais não está prevista apenas na matriz da prova de LCTs, também nas matrizes das outras áreas do conhecimento, como na de Matemática, Códigos e suas Tecnologias, por meio da habilidade 25 : Identificar, em textos de diferentes gêneros, as marcas linguísticas que singularizam. O que se 
justifica pelo fato de muitas questões da área de matemática serem constituídas por meio de situação-problema. Diante disso, um candidato que realiza o Enem é avaliado a partir das competências e habilidades que são previstas em uma matriz, que se pauta na proficiência em leitura e no reconhecimento dos gêneros textuais para fins da resolução das questões e obtenção de resultados satisfatórios.

\subsection{Enade enquanto avaliação em larga escala e concepções de leitura subjacentes}

Haja vista que as avaliações em larga escala permeiam a educação do país em todos os seus niveis, no que se refere à educação superior, o Enade é uma avaliação de caráter obrigatório e avalia o rendimento dos ingressantes e concluintes dos cursos de graduação, em relação aos conteúdos programáticos, habilidades e competências adquiridas em sua formação. Sua primeira aplicação ocorreu em 2004 e a periodicidade máxima da avaliação é trienal para cada área do conhecimento.

O objetivo do Enade é avaliar o desempenho dos estudantes com relação aos conteúdos programáticos previstos nas diretrizes curriculares dos cursos de graduação, o desenvolvimento de competências e habilidades necessárias ao aprofundamento da formação geral e profissional, integrando o Sistema Nacional de Avaliação da Educação Superior (Sinaes), responsável por avaliar a qualidade dos cursos e instituições de educação superior de todo o Brasil e promover o desenvolvimento de políticas públicas para a educação superior.

Para a edição de 2017, de acordo com a edital n. ${ }^{\circ} 26$, de 16 de junho de 2017, convoca os alunos que se enquadram nos seguintes perfis:

1.4.1.1 Inscrição dos Estudantes Irregulares: Estudantes habilitados no ENADE de anos anteriores que, por qualquer razão, permaneceram em situação irregular e não foram beneficiados por dispensa oficial concedida pelo MEC. A IES deverá inscrevê-los para regularização de sua situação junto ao ENADE, no entanto, esses Estudantes não realizarão o Exame.

1.4.1.2 Inscrição dos Estudantes Ingressantes: Estudantes que tenham iniciado o respectivo curso no ano de 2017, devidamente matriculados, e que tenham até vinte e cinco por cento da carga horária mínima do currículo do curso cumprida até o último de retificação, no entanto, esses Estudantes não realizarão o Exame.

1.4.1.3 Estudantes Concluintes dos Cursos de Bacharelado e Licenciatura: Estudantes que tenham expectativa de conclusão do curso até julho de 2018 ou que tenham cumprido oitenta por cento ou mais da carga horária mínima do curriculo do curso da IES até o dia de retificação;

1.4.1.4 Estudantes Concluintes dos Cursos Superiores de Tecnologia: Estudantes que tenham expectativa de conclusão do curso até dezembro de 2017 ou que tenham cumprido setenta e cinco por cento ou mais da carga horária mínima do currículo do curso da IES até o dia de retificação (BRASIL, 2017, p. 28).

Em linhas gerais, devem fazer o exame alunos que estejam iniciando a graduação, concluintes ou aqueles que estejam irregulares, uma vez que o mesmo é de caráter obrigatório para os alunos selecionados e condição indispensável para a emissão do histórico escolar.

A prova aplicada é composta por duas partes, uma de conhecimentos especificos da área de formação e a outra de Formação Geral, comum aos cursos de todas as áreas, com 10 questões, 2 discursivas e 8 de múltipla escolha. Nas questões discursivas são avaliados aspectos como clareza, coerência, coesão, estratégias argumentativas, utilização de vocabulário adequado e correção gramatical do texto.

Como o Enade se subdivide na aplicação de duas provas, uma voltada para os conhecimentos especificos de cada curso; e a outra de conhecimento comum a todas as áreas, além do nosso objeto de estudo ser a proficiência em leitura, adotaremos como documento norteador do exame os concernentes à área de Formação Geral, haja vista ser essa a que todos os estudantes devem fazer.

Quanto às características exigidas dos alunos, a Portaria do Inep n. ${ }^{\circ} 294$ de 8 de junho de 2016, com as definições estabelecidas pela Comissão Assessora de Área de Formação Geral, define:

I. fazer escolhas éticas, responsabilizando-se por suas consequências;

II. ler, interpretar e produzir textos com clareza e coerência;

III. compreender as linguagens como veículos de comunicação e expressão, respeitando as diferentes manifestações étnico-culturais e a variação linguistica; 
IV. interpretar diferentes representações simbólicas, gráficas e numéricas de um mesmo conceito;

$\mathrm{V}$. formular e articular argumentos consistentes em situações sociocomunicativas, expressando-se com clareza, coerência e precisão;

$\mathrm{VI}$. organizar, interpretar e sintetizar informações para tomada de decisões;

VII. planejar e elaborar projetos de ação e intervenção a partir da análise de necessidades, de forma coerente, em diferentes contextos;

VIII. buscar soluções viáveis e inovadoras na resolução de situações-problema;

IX. trabalhar em equipe, promovendo a troca de informações e a participação coletiva, com autocontrole e flexibilidade;

X. promover, em situações de conflito, diálogo e regras coletivas de convivência, integrando saberes e conhecimentos, compartilhando metas e objetivos coletivos (BRASIL, 2016, p. 2. grifo nosso).

Dentre as 10 habilidades, pelo menos seis fazem menção direta à leitura, o que corrobora com a premissa de que a leitura e a escrita acadêmica são ponto fundamental para um bom desempenho do aluno na universidade, uma vez que, ao fazer a prova do Enade, os estudantes contribuirão com a composição da nota que avalia a instituição da qual fazem parte.

Assim como no Enem, ${ }^{5}$ a prova de Formação Geral do Enade também prevê questões objetivas de múltipla escolha e questões de cunho discursivo, nas quais o aluno deve produzir pequenos textos para apresentar suas respostas. Ainda é possivel identificar outras semelhanças. Em termos de avaliação em leitura, o foco principal do Enade é voltado para a interpretação textual e, no que se refere à produção de texto, através das questões discursivas da prova, a proposta se pauta na organização e concisão, coesão e clareza das ideias, também sendo necessário o domínio dos gêneros textuais.

Ao observar as questões da prova de Formação Geral de 2012, Silva e Costa (2014, p. 129) apontam que "a prova do Enade 2012 apresentava questões, em sua maioria, que exigiam do candidato um conhecimento prévio do assunto apresentado, além de muita leitura, pois antes de cada questão foi apresentado um texto como subsidio". Como resultado da análise, os pesquisadores descrevem que, das oito questões de múltipla escolha, todas exigiram, do estudante, capacidade de interpretação textual, por meio de habilidades de leitura e conhecimento de mundo para identificar a alternativa correta.

Partindo da prerrogativa de que uma das possibilidades de avaliar o desempenho dos estudantes é por meio das avaliações, e se o objetivo for obter resultados em escalas maiores, as avaliações em larga escala se tornam um dos principais meios para atingir esse fim, uma das alternativas mais eficientes para observar o desempenho de alunos universitários em leitura é o exame que seleciona os candidatos para as vagas nas universidades e o que avalia o seu desempenho durante o curso das atividades acadêmicas, o Enem e o Enade, respectivamente.

Desse modo, as variáveis que compõem os in-
dices de qualidade de uma IES ou de um curso,
considerando os processos de avaliação exter-
na, atualmente, no Brasil, são os desempenhos
acadêmicos dos ingressantes (Enem - a partir
de 2011) e concluintes do Exame Nacional de
Desempenho do Estudante (Enade), a infraes-
trutura, a titulação e o regime de trabalho do
corpo docente e a condição sociocultural dos
alunos. É inegável que todas elas são impor-
tantes na formação do conceito de qualidade
institucional (DIAS; PORTO; NUNES, 2016, p. 2).

As duas provas se configuram como um meio possivel de coletas de informações e dados para balizar a discussão aqui proposta, sobre a relação do ingresso, permanência e sucesso estarem relacionados ao desempenho em leitura.

\section{Leitura e escrita no contexto acadêmico}

Partindo da perspectiva de que o aluno que ingressa na educação superior já passou por, pelo menos, 12 anos de escolarização (nove no ensino fundamental e três no ensino médio), e da colocação de Witter (1997, p. 11), "Certamente as contingências de vida anterior ao ingresso na universidade, o nivel de desempenho em leitura com que nela ingressa e as condições atuais de vida do estudante, são variáveis que influenciam na leitura 
do universitário"; parte-se da premissa de que esses já adentraram a educação superior dominando satisfatoriamente as competências e habilidades em leitura e escrita concernentes às exigências dos cursos nos quais se matricularam, uma vez que, ao prestar um exame de seleção, normalmente o Enem, os estudantes já foram avaliados.

Essa premissa culmina na oferta ou não de disciplinas específicas para a abordagem das práticas de leitura e escrita, a exemplo das disciplinas de Produção Textual, ofertadas logo nos primeiros periodos letivos, principalmente quando existem questionamentos, por vezes até por parte de alguns professores, quanto a real necessidade da presença das mesmas nas grades curriculares, como evidencia Marinho (2010), ao apontar que esses docentes, por considerarem que o aluno aprovado no vestibular teria sido avaliado nas suas habilidades de leitura e escrita e, consequentemente, estaria apto a ler com propriedade e familiaridade os textos acadêmicos. Em oposição a essa ideia, a autora defende:

[...] torna-se mais coerente esperar e aceitar que os alunos universitários se familiarizem e aprendam a ler e a escrever os gêneros acadêmicos, sobretudo, nas instituições e nas esferas do conhecimento em que são constituidos, portanto, quando se inserem nas práticas de escrita universitária (MARINHO, 2010, p. 366).

Ao ingressar na universidade, o estudante já teve contato com práticas de leitura e escrita, porém essas foram concernentes ao contexto proposto para a educação básica, o que não o leva, necessariamente, a ter experiências mais aprofundadas, por exemplo, com os gêneros acadêmicos. Desse modo, o aluno é imerso em um mundo de saberes no qual ele é leigo. De acordo com Tourinho (2011, p. 341), "o estudante de nivel superior se assusta com a realidade que não é sua, a de ter que estar as voltas com enormes quantidades de leituras exigidas, seguidas de uma extensa labuta com a escrita interpretativa dessas leituras".

É possivel exemplificar essa realidade por meio da experiência de um aluno que concluiu o ensino médio e ingressou na universidade através do Enem. Ao fazer a prova de redação, o candidato tem que, consoante à Matriz de
Referência elaborada pelo MEC, a partir de uma situação-problema e de subsidios oferecidos, realizar uma reflexão escrita sobre um tema de ordem política, social ou cultural, produzindo um texto do tipo dissertativo-argumentativo.

Ao texto dissertativo, Travaglia (2007, p. 60) atribui como função: "na dissertação busca-se o refletir, o explicar, o avaliar, o conceituar, expor ideias para dar a conhecer, para fazer saber, associando-se à análise e à síntese de representações", e ainda quanto ao texto dissertativo-argumentativo, complementa: "Como se sabe, os textos do tipo argumentativo stricto sensu têm sempre por objetivo convencer e, mais ainda, persuadir o alocutário a fazer algo, ou a participar de certo modo de ver os fatos, os elementos do mundo".

Diante disso, o que se espera do candidato que faz a prova de redação é que ele seja capaz de desenvolver um texto de forma crítica a partir de um tema estabelecido, em um padrão estrutural também já estabelecido. Isso leva à expectativa de que, por mais que, na educação básica, o aluno tenha contato com os mais diversos gêneros textuais, vai ser maior objeto de estudo e de prática textual o dissertativo cobrado nos exames de seleção de vagas, já que é na escola que o candidato se prepara esse tipo de prova.

Ademais, ainda sobre o gênero dissertativo-argumentativo, Travaglia (2007, p. 56) apresenta como exemplos tese, dissertação de mestrado, artigo acadêmico-científico, editorial de jornal, monografia, conferência, artigo de divulgação científica, entre outros, ou seja, gêneros de grande circulação no meio acadêmico. Isso evidencia que o tipo textual mais recorrente nas séries finais da educação básica é o mesmo da educação superior, todavia não são abordados de forma mais aprofundada quanto às suas particularidades estruturais, ficando a cargo da universidade desenvolver essa competência em seus alunos, como evidenciam Medeiros e Silva (2012, p. 125): "Os gêneros acadêmicos encontram-se em condições de produção determinadas e inseridas em práticas comunicativas institucionalizadas, ou seja, possuem conteúdo temático delimitado, inserido dentro de uma dada área da ciência". 
Nessa mesma linha de quebra de expectativa, de que o aluno já adentre na universidade munido da bagagem necessária para desempenhar satisfatoriamente as atividades que envolvam leitura e escrita, Cabral e Tavares (2005) criaram um questionário voltado para a avaliação do nível de competência, grau de dificuldade e disponibilidade em receber informações especializadas, a fim de obter dados e subsidiar a existência de relação entre desempenho em leitura e escrita e sucesso acadêmico.

Ao obter dados de mais de 1000 alunos, em quatro universidades diferentes, os pesquisadores identificaram que os estudantes, face às especificidades dos objetivos e tipos de textos inerentes às atividades de escrita acadêmica, interiorizam as estratégias especificas da escrita acadêmica na universidade. No tocante à leitura, o estudo revela que as estratégias utilizadas pelos alunos tendem para a realização de atividades pouco significativas, devido aos métodos mecânicos e repetitivos, com tendência à reprodução de conteúdo e memorização de informações.

Outro ponto relevante da pesquisa de Cabral e Tavares (2005) é a mudança de abordagem de aprendizagem ao longo dos periodos letivos. Para um aluno do primeiro período, a tendência é apresentar um domínio bem mais raso de conhecimento adquirido a partir das atividades de leitura, se comparado com alunos do quarto período, que apresentaram uma abordagem mais profunda e crítica daquilo que foi lido. De modo que, por meio dos dados obtidos, foi possivel confirmar que é na IES que os estudantes adquirem e desenvolvem maior proficiência em leitura e escrita, corroborando com a premissa de Marinho (2010) e Fiad (2011), sobre a necessidade de oferta de disciplinas especificas para esse fim.

Ainda sobre dados empíricos, pesquisas realizadas por Silva e Santos (2004) e Freitag et al. (2014), ambas por meio de teste cloze, avaliaram o desempenho em compreensão leitora de universitários. Ao aplicar 782 testes, em oito cursos diferentes, nas áreas de licenciatura e bacharelado, Silva e Santos (2004, p. 465) concluem que: "O número médio de acertos ficou abaixo do que se espera para alunos universitários, demonstrando que os estudantes possuem nivel de compreensão aquém do desejado para obter os conhecimentos necessários no nivel superior". Ainda mais preocupante, os resultados do teste aplicado por Freitag et al. (2014) revelou a existência de um déficit com relação à proficiência em leitura presente em 100\% dos sujeitos observados.

Em comum, os estudos de Cabral e Tavares (2005), Silva e Santos (2004) e Freitag et al. (2014), além da constatação da falta de bagagem necessária para desempenhar de modo eficiente as atividades de leitura e escrita acadêmicas, evidenciam a relação entre ser proficiente e apresentar um desempenho acadêmico melhor.

\begin{abstract}
Considera-se que este estudo vem, de certa forma, fundamentar a ideia de que as competências de leitura/compreensão e escrita desempenham um papel central no contexto do ensino superior. A atenção nos dados obtidos, observa-se que estes remetem para um índice de utilização elevado de ambas as competências (sem que diferissem estatisticamente), fundamentalmente por razões relacionadas com as tarefas acadêmicas e que, de entre as estratégias apresentadas, as mais utilizadas corresponderam às que encerram um menor grau de complexidade e se aplicam mais diretamente às necessidades imediatas dos estudantes aproximando-se de uma abordagem superficial de aprendizagem (CABRAL; TAVARES, 2005, p. 201).
\end{abstract}

Sendo ainda mais incisivo, Tourinho (2011) indica que o problema da absorção simples de conhecimento exigidos pelos cursos de graduação, por meio da leitura, tem se mostrado como um fator relevante de evasão, uma vez que a dificuldade dos alunos é evidente quando são cobrados a realizar tarefas que exijam interpretação de texto, por exemplo. E por isso, propõe ser de grande relevância conhecer o aluno-leitor desde o momento que esse ingressa na universidade, como acompanhá-lo ao longo do curso. Quanto as estratégias de abordagem pelos professores, Medeiros e Silva (2012) propõem:

Para o professor reconhecer as dificuldades de seus alunos na leitura e na produção de um determinado gênero, é interessante que ele saiba antes quais são os conhecimentos dos seus alunos sobre tais gêneros, em seguida, apresente modelos e análises desses gêneros e, por fim, solicitar a atividade de produção (MEDEIROS; SILVA, 2012, p. 126). 
Diante dos estudos aqui apresentados, fica evidente que um dos grandes problemas enfrentados nas universidades atualmente decorre do conflito entre o que se espera que o aluno que ingressa na universidade domine e o que ele domina, efetivamente, em termos de aprendizagem, principalmente no que corresponde à proficiência em leitura. Conflito esse que pode ser um dos maiores responsáveis pelos baixos indices de egressos nas universidades. A respeito dessa realidade, é preciso observar criticamente o fato de os alunos prestarem um exame de seleção para ingressar na educação superior, sendo inclusive o objetivo de número VII da matriz do Enem - promover a avaliação de desempenho acadêmico de ingressantes nas Instituições de Educação Superior, ou seja, torna-se uma medida alternativa para a prova do Enade quando destinada aos alunos no início das atividades acadêmicas. Assim, é preciso avaliar como dá-se a coexistência de duas avaliações nessa modalidade de ensino, com as grades curriculares dos cursos de graduação, a fim de identificar uma unidade ou não das premissas de aprendizagem e desempenho dos alunos.

\section{Enem, Enade e as demandas de leitura da educação superior}

Enem e Enade apontam em seus documentos norteadores semelhanças no que corresponde a concepção de leitura e escrita nas suas avaliações, ambas adotam a leitura a partir da perspectiva de interpretação das informações e solucionar situações-problema, e a escrita através da noção de tipos e gêneros textuais, principalmente o dissertativo, além de domínio em aspectos de organização textual, a exemplo da coesão e coerência.

Sendo que uma avaliação corresponde à avaliação do ingresso - Enem e a outra do egresso - Enade, é preciso observar o processo de aprendizagem do aluno ao longo dos cursos de graduação, a respeito do que é exigido dos mesmos para o curso das disciplinas.

Assim como as duas avaliações apresentam documentos norteadores, a exemplo da matriz e da portaria, os cursos de graduação são balizados pelas grades curriculares, compostas pela carga-horária e disciplinas obrigatórias e optativas que os estudantes devem cursar. Apesar de os cursos de graduação serem de áreas do conhecimento diferentes, e em cada uma delas o domínio em leitura terem as suas exigências especificas, estudos aqui já apontados, como os Marinho (2010) e Fiad (2011), Tourinho (2011) e Medeiros e Silva (2012) indicam a importância da oferta de disciplinas voltadas para esta finalidade, a exemplo de disciplinas como Produção e Recepção de Texto, devido a necessidade de preparar os alunos para as especificidades dos seus respectivos cursos.

Ainda a despeito da existência de áreas distintas, a pesquisa realizada por Freitag et al. (2014) foi desenvolvida com alunos que cursam Química licenciatura, na qual se identificou a existência de um déficit de proficiência em leitura em 100\% dos sujeitos observados. Em se tratando de alunos de um curso da área de exatas, existe um estigma de que as dificuldades leitoras são concernentes àqueles que optam por trabalhar com cálculos e não com as humanidades, todavia, em outra pesquisa, Freitag et al. (2010) observam alunos de um curso preparatório para vagas do ensino superior, sejam eles pretendentes às vagas dos mais diversos cursos (humanas, biológicas, exatas), constatando a fragilidade no desenvolvimento de competências e habilidades relativas à leitura de nossos potenciais futuros graduandos, revelando uma bagagem insuficiente para o trabalho com essa habilidade em domínios mais complexos da esfera do letramento.

Além disso, sobre o periodo de transição, educação básica e educação superior. Pietre (2007) desenvolveu uma pesquisa voltada para a análise de redação de vestibulares, com o objetivo de investigar a escrita escolar a partir dos primeiros artigos divulgados pela Fundação Carlos Chagas sobre as produções textuais de alunos que fizeram seleções vestibulares. Sua análise chega à conclusão de que, desde os primeiros levantamentos de dados, os alunos tendem para uma reprodução continuada de fórmulas decorrente de um ensino pautado em treinamentos. Como consequência, apresentam 
textos com pouca informação e criticidade, reduzidos à reprodução e atendimento das questões normativas da gramática.

Quando se pensa no estilo mais recente de prova de redação utilizada no país, a redação do Enem, é possivel vislumbrar uma realidade muito semelhante, haja vista que o critério de atribuição de nota está pautado em cinco competências, que exigem do aluno o domínio de aspectos gramaticais e de argumentação. A indicação daquilo que será cobrado do aluno justifica a corrida pelos cursos preparatórios que possam indicar os "caminhos" para se tingir a nota máxima na redação. Além desses cursos, muitos candidatos têm recorrido aos aplicativos de correção on-line, que, segundo pesquisa realizada em 2015 pela Empresa Brasil de Comunicação (EBA), tem 90\% dos usuários candidatos às vagas do Enem (EBA, 2015).

Fica mais evidente constatar essa quebra de expectativa, de que os alunos estão preparados para a produção acadêmica, quando se observa a gama de gêneros textuais inerentes ao contexto acadêmico e suas diferentes características e finalidades, uma vez que esses textos são produzidos e circulam entre professores e alunos no âmbito universitário com diferentes propósitos comunicativos, que vão desde as atividades avaliativas da sala de aula até a divulgação de pesquisas, como ditos por Mota-Roth e Hendges (2010, p. 23): "cada gênero é reconhecido de forma particular em sua construção textual, seja um artigo, um abstract, uma monografia, um livro, há funções diferentes que o envolvem: tema e objetivo do texto, público-alvo, e organização das informações".

Entendendo o texto acadêmico como uma produção que deve atender às normas técnicas e que se apresente de modo claro, objetivo e com relevância científica, é possivel evidenciar que não se trata de uma tarefa fácil de execução. Como aponta Coracini (1991), ao afirmar que a linguagem científica requer um conhecimento aprofundado dos recursos linguísticos empregados pela comunidade cientíica e não somente conhecer a sua estrutura formal.

Para Barros (2009), é possivel organizar os gêneros acadêmicos em três grupos: Gêneros didáticos: Resumos, Resenhas, Relatórios, Projetos e outros. Gêneros de divulgação: Artigos, Resenhas, Ensaios. Gêneros de conclusão e/ou aquisição de grau: Monografia, Ensaio, Dissertação, Tese, Memorial. Cada um com estrutura e finalidades específicas, a exemplo do resumo, voltado para a descrição da parte, capítulo ou da integra de um livro; e a resenha, que exige a análise do que foi lido e não somente a descrição, sinalizando, assim, que cada gênero tem suas especificidades de estrutura.

Não obstante, não é a forma que caracteriza a única exigência na produção dos mais diversos gêneros acadêmicos, mas a escrita de caráter comunicativo, aspecto apontado como de primordial domínio já na educação básica, que será avaliada no Enem. Ao ingressar na educação superior, o que se espera é que o aluno produza textos a partir de uma linguagem comunicativa, voltada para as práticas sociais, haja vista que sua produção irá circular no meio acadêmico com a finalidade de compartilhar os conhecimentos adquiridos, assim como evidenciado por Marcuschi (2008, p. 150), ao afirmar que os gêneros não são entidades formais, mas sim "entidades comunicativas em que predominam os aspectos relativos a funções, ações conteúdos, pode-se dizer que a tipicidade de um gênero vem de suas características funcionais e organizações retóricas".

Diante disso, a presença de disciplinas, na grade curricular dos cursos, voltadas para a abordagem de leitura e escrita, já que muitos alunos se preparam para o Enem por meio de métodos reprodutivos de fórmulas e não por meio da construção crítica do conhecimento, o que afetará negativamente o desempenho do aluno ao longo do curso e possivelmente também no Enade.

Todavia, a oferta não é unânime nos cursos de graduação, como aponta Fiad (2011, p. 361), ao observar a escrita acadêmica de alunos do curso de Letras da Unicamp durante o periodo que foi professora da disciplina Prática de leitura e produção de textos, passou a problematizar o fato de a disciplina ter sido extinta da grade curricular devido à "crença de que os alunos que entravam na universidade dominavam alguns gêneros do 
discurso e que o ensino dos gêneros acadêmicos deveria acontecer em situações de escrita no interior das diferentes disciplinas do currículo".

A realidade é que, normalmente, esse tipo de disciplina fica com oferta restrita aos cursos das áreas de humanidades, a exemplo das duas disciplinas oferecidas pela Universidade Federal de Sergipe aos alunos ingressos no curso de Letras, as disciplinas Produção de Texto I e ll logo nos dois primeiros periodos, porém, como já discutido, as dificuldades em proficiência em leitura e escrita não são concernentes apenas aos estudantes dos cursos de humanas. Em decorrência da carência da oferta de disciplinas, entra em questão a importância das políticas de permanência estudantil de cunho pedagógico como uma alternativa aos estudantes que não têm as disciplinas nas Grades curriculares dos seus cursos.

\section{Considerações finais}

Considerando que o leitor proficiente é definido como alguém que atribui sentido enquanto lê, não restringe o significado na palavra lida, que se utiliza de estratégias para ampliar os significados e atribuir novos sentidos, e ainda, segundo Solé (1998), o leitor proficiente é capaz de aprender a partir dos textos lidos, capaz de interrogar-se sobre sua compreensão, estabelecer relações entre o que lê e o que faz parte do seu acervo pessoal, espera-se que um individuo, ao cursar as séries da educação básica, adentrarem na educação superior e concluírem seus cursos de graduação, adquiram todas as habilidades necessárias para serem leitores competentes.

Todavia, como quebra dessa perspectiva, dados como o do Índice de Analfabetismo Funcional (Inaf) de 2018, apontam que 13\% dos que concluem o ensino médio e $4 \%$ dos que atingem o nivel superior de escolaridade são analfabetos funcionais, o que leva a entender que o processo educacional não atende à demanda de formação eficiente dos seus estudantes, pelo menos não no que tange à leitura, mesmo que avaliações como o Enem, que avalia os estudantes que concluem o ensino médio e os selecionam para ocupar vagas na educação superior, e o Enade. que avalia os cursos com estantes em fase de conclusão, tenham prevista, em seus documentos norteadores, a prerrogativa de formação e avaliação do leitor proficiente.

A análise dos documentos aponta para o fato de, apesar do reconhecimento da importância da formação de um leitor proficiente em um contexto de educação de qualidade e mesmo que o sistema educacional seja de escala gradativa, educação infantil, básica e superior, há uma falta de unidade e os problemas se perpetuam de modo que ainda existam individuos que concluem a escolaridade em nível superior na situação de analfabeto funcional, algo extremamente grave e que revela a necessidade de revisão das práticas pedagógicas adotadas ao longo de todo o sistema de educação vigente, a fim de que atendam o que preconizam os documentos.

\section{Referências}

ALMEIDA, Ayane Nararela Santos; FREITAG, Raquel Meister Ko. Análise do diagnóstico do desempenho em leitura: Provinha Brasil vs. fluência em leitura oral. Signo, Santa Cruz do Sul, v. 37, n. 63, p. 98-110, 2012.

ANDRADE, Sammela Rejane de Jesus. Práticas de escrita na universidade: um olhar sob a redação do Enem e a apropriação dos gêneros acadêmicos. In: AZEVEDO, Isabel Cristina Michelan de; ROIPHE, Alberto (org.). Leitura, escrita e literatura: interseções e convergências. São Cristóvão: Editora UFS, 2016.

BARROS, Juliene da Silva. Margens do texto científico Disponivel em: http://www.uag.ufrpe.br/docs/Juliene_Ill.pdf. Acesso em: 22 jan. 2020.

BLOOM, B. S. et al. Taxonomy of educational objectives. New York: David Mckay, 1956.

BRASIL. Institui o Programa de Apoio a Planos de Reestruturação e Expansão das Universidades Federais - REUNI. Decreto n 6.096, de 24 de abril de 2007. Brasilia, DF: MEC, 2007.

BRASIL. Instituto Nacional de Estudos e Pesquisas Educacionais Anísio Teixeira. ENEM - Documento Base. Brasilia, DF: MEC, 2000.

BRASIL. Instituto Nacional de Estudos e Pesquisas Educacionais Anisio Teixeira. Matriz de Referência. Brasilia, DF: INEP, [2015?]. Disponivel em: http://download.inep. gov.br/download/enem/matriz_referencia.pdf. Acesso em: 15 jan. 2020.

BRASIL. Instituto Nacional de Estudos e Pesquisas Educacionais Anísio Teixeira. Portaria n. 294, de 8 de junho de 2016 - Dispõe sobre o componente de Formação Geral do Enade 2016. Brasília, Distrito Federal, 2016. 
BRASIL. Instituto Nacional de Estudos e Pesquisas Educacionais Anísio Teixeira. Portaria n. 493, de 6 de junho de 2017- Dispõe sobre o componente de Formação Geral do Enade 2017. Brasilia, Distrito Federal, 2017.

BRASIL. Instituto Nacional de Estudos e Pesquisas Educacionais Anisio Teixeira. Pisa. Disponivel em: http:// www.inep.gov.br/pisa-programa-internacional-de-avaliacao-dealunos. Acesso em: 08 dez. 2019.

BRASIL. Ministério da Educação. Lei n.9394, de 20 de dezembro de 1996 - Estabelece as diretrizes e bases da educação nacional. Brasília, Distrito Federal, 1996.

BRASIL. Ministério da Educação e Instituto Nacional de Estudos e Pesquisas Educacionais Anísio Teixeira. Matriz de Referência para o ENEM 2009. Brasilia, Distrito Federal, 2009.

BRASIL. Parâmetros curriculares Nacionais. Brasília: DF, 1998.

BRASIL. Parâmetros curriculares Nacionais do Ensino Médio. Brasilia: DF, 1997.

CABRAL, Ana Paula. TAVARES, José. In: Leitura/compreensão, escrita e sucesso acadêmico: um estudo de diagnóstico em quatro universidades portuguesas. Psicologia Escolare Educacional, [S. l.], v. 9. n. 2, p. 203-213, 2005. https://doi.org/10.1590/S1413-85572005000200003.

CAVALCANTI, Rosilene da Silva de Moraes. BENITES, Sonia Aparecida Lopes. A proposta de leitura do Enem. In: IV CONALI - Congresso Nacional de Linguagens em Interação Múltiplos Olhares, 2013. Anais eletrônicos do [...]. ISSN: 1981-8211

CORACINI Maria José R. Faria. Um fazer persuasivo: o discurso subjetivo da ciência. São Paulo: Educ; Campinas: Pontes, 1991.

DIAS, Juliana da Silva. PORTO, Cristiane de Magalhães. NUNES, Andrea Karla Ferreira. Formação geral e conhecimento específico na prova ENADE. 2017. Anais eletrônicos do 11 Enfope e 12 Fopie. Disponivel em: https://eventos.set.edu.br/index.php/enfope/article/ view/2056. Acesso em: 25 jan. 2018.

FIAD, Raquel Salek. A escrita na universidade. Rev. da Abralin. (on-line), [S. l.], p. 357-369, 2011. https://doi. org/10.5380/rabl.v10i4.32436.

FREITAG, Raquel Meister Ko et al. Diagnóstico da competência de leitura de pré-vestibulandos: experiência no Pré-SEED em Itabaiana, Estado do Sergipe. Acta Scientiarum: Language and Culture, Maringá, v. 32, n. 2, p. 233-240, 2010. https://doi.org/10.4025/actascilangcult.v32i2.7327.

FREITAG, Raquel Meister Ko et al. Teste cloze e a competência em leitura de universitários: uma experiência no curso química/licenciatura da UFS/Itabaiana. Interscienceplace, [S. l.], n. 30, v. IX, jul./ set. 2014. https://doi. org/10.6020/1679-9844/3001.

FREITAG, Raquel Meister Ko; ALMEIDA, Ayane Nazarela Santos; ROSÁRIO, Mônica Maria Soares. Contribuições para o aprimoramento da Provinha Brasil enquanto instrumento diagnóstico do nível de alfabetização e letramento nas séries iniciais. Revista Brasileira de Estudos Pedagógicos, [S. L.], v. 94, n. 237, p. 390-416, 2013. https://doi.org/10.1590/S2176-66812013000200004.
FREITAG, Raquel Meister Ko; DE SANTANA SÁ, José Junior. Leitura em voz alta, variação linguística e o sucesso na aprendizagem inicial da leitura. Ilha do Desterro, [S. l.], v. 72, n. 3, p. 41-62, 2019. https://doi. org/10.5007/2175-8026.2019v72n3p41.

FREITAG, Raquel Meister Ko. Reparos na leitura em voz alta como pistas de consciência sociolinguistica. (no prelo)

FREITAG, R. M. K. O desenvolvimento da consciência sociolinguística e o sucesso no desempenho em leitura. (no prelo)

GADOTTI, M. Uma escola para todos os caminhos da autonomia escolar. Petrópolis. Ed. Vozes, 1991.

MACHADO, Alessandra Pereira Gomes; MATOS, Andréa Maria dos Santos. Compreensão Leitora na Resolução de Problemas na Prova Brasil de Matemática. Signum: Estudos da Linguagem, [S. l.], v. 22, n. 1, p. 88-113, 2019. https://doi.org/10.5433/2237-4876.2019v22n1p88.

MARCUSCHI, Luiz Antônio. Gêneros textuais: definição e funcionalidade. In: DIONISIO, A. P.; MACHADO, A. R.; BEZERRA, M. A. (org.). Gêneros textuais e ensino. 4. ed. Rio de Janeiro: Lucerna, 2005.

MARCUSCHI, Luiz Antônio. Produção textual, análise de gêneros e compreensão. São Paulo: Parábola, 2008.

MARINHO. Marildes. A escrita nas práticas de letramento acadêmico. RBLA, Belo Horizonte, p. 363-386, 2010. https://doi.org/10.1590/S1984-63982010000200005.

MEDEIROS, Célia Maria de. SILVA, Denize C. Práticas de leitura e escrita na academia: saberes na esfera cientifica. Caderno de monitoria, Natal v. 1, n. 3, p. 123-136, 2012.

MOTTA-ROTH, Désirée; HENDGES, Graciela. Produção textual na universidade. São Paulo: Parábola, 2010.

OCDE. Organização para a Cooperação Econômica e Desenvolvimento. Relatórios Econômicos da OCDE: Brasil 2018. Disponivel em: http://www.oecd.org/economy/surveys/Brazil-2018-OECD-economic-survey-overview-Portuguese.pdf. Acesso em: 03 mar. 2020.

PIETRE, Emerson de. A constituição da escrita escolar em objeto de análise dos estudos linguísticos. Linguistica Aplicada, Campinas, v. 46, n. 42, p. 283-297, 2007. https://doi.org/10.1590/S0103-18132007000200010.

SILVA, Maria José Moraes da Silva. SANTOS, Acácia aparecida A. dos. A avaliação da compreensão em leitura e o desempenho acadêmico de universitários. Psicologia em Estudo, Maringá, v. 9, n. 3, p. 459-467, 2004. https://doi.org/10.1590/S1413-73722004000300014.

SILVA, Marliane Dias; COSTA, João Gabriel Lima. O uso das estratégias de leitura: a questão chave da prova de Formação Geral do ENADE 2012. Revista Científica do Centro de Ensino Superior Almeida Rodrigues, [S. l.], a. II, ed. II, p. 126-130, 2014.

SOLÉ, Isabel. Estratégias de leitura. 6. ed. Porto Alegre: ArtMed, 1998.

SOUZA, Victor Renê Andrade; SILVA, Vitória Laís Santos; ARAUJO JUNIOR, Mauro Monteiro. Da fala à leitura: variação linguística na leitura em voz alta de estudantes da Universidade Federal de Sergipe. Porto das Letras, [S. l.], v. 6, p. 1-29, 2020. 
TOURINHO, Cleber. Refletindo sobre a dificuldade de leitura dos alunos do Ensino superior: "deficiência" ou simples falta de hábito? Revista Lugares da Educação, Paraíba, v. 1, n. 2, p. 325-346, 2011. https://doi. org/10.18788/2237-1451/rle.v1n2p325-346.

TRAVAGLIA. Luiz Carlos. A caracterização de categorias de texto: tipos, gêneros e espécies. Alfa, São Paulo, p. 39-79, 2007.

WITTER, Geraldina. Leitura e Universidade. Campinas: Editora Alínea, 1997.

ZIRONDI, Maria Ilza. NASCIMENTO, Elvira Lopes. Os Enunciados de Comando da Prova do ENEM e sua Relação com Competências e Capacidades para a Resolução de Situações-Problema. Signum: Estud. Ling., Londrina, n. 9/2, p. 289-315, dez. 2006. https:// doi.org/10.5433/2237-4876.2006vgn2p289.

\section{Sammela Rejane de Jesus Andrade}

Doutora em Educação pela Universidade Federal de Sergipe (UFS), em Sergipe, SE, Brasil.

\section{Endereço para correspondência}

Sammela Rejane de Jesus Andrade

Rua Tobias Barreto, 238

Centro, 49500247

Itabaiana, SE, Brasil 